\title{
HIGH K LOW LOSS DIELECTRICS CO-FIREABLE WITH LTCC*
}

\author{
CHRISTINA MODES ${ }^{\mathrm{a}, \uparrow}$, STEFAN MALKMUS $^{\mathrm{b}}$ and FRIEDER GORA ${ }^{\mathrm{c}}$ \\ ${ }^{a}$ W.C. Heraeus GmbH \& Co KG, Circuit Materials, 12-14 Heraeusstrasse D-63450 Hanau, \\ Germany; ${ }^{\mathrm{b}}$ Quentin Reynolds, Heraeus Materials Ltd, Canada Road, Byfleet, Surrey KT14 $7 \mathrm{JL}$, \\ Wolfram Wersing, Oliver Dernovsek, Siemens AG, CT MM2, 6 Otto-Hahn-Ring D-81730 Munich, \\ Germany; ${ }^{\mathrm{c}}$ Wolfgang Schiller, Bundesanstalt für Materialforschung und -prüfung, BAM-V.4 44-46 \\ Unter den Eichen, D-12203 Berlin, Germany
}

(Received December 2001)

\begin{abstract}
Rapid growth in the application of LTCC technology for RF wireless is clearly driven by the trend of miniaturization and mobile communication systems. This technology provides the possibility of integration of passive components in a cost effective way. Heraeus has implemented compatible high permitivity and low loss dielectrics with NPO performance into modified Heraeus CT700 low temperature co-fired ceramic tape system. The majority of commercially available microwave dielectrics show increasing firing temperatures $>1200{ }^{\circ} \mathrm{C}$ which make them incompatible with $\mathrm{Ag}$ metallizations or show high dielectric loss which limit their usage in RF wireless applications. This development work demonstrates the integration of a low loss, high permittivity $\varepsilon=60$ dielectric tape into a conventional Ag bearing LTCC structure. The concept of a dual sintering process is introduced and the resultant mechanical benefits with regard to tape fired shrinkage are explained in detail. Permittivity and dielectric loss data at RF for the new structure are presented. These high $\mathrm{K}$ and low loss dielectrics along with a comprehensive material system developed by Heraeus will support customers in meeting the challenges of reducing cost and enhancing the performance of RF devices for high frequency applications.
\end{abstract}

Keywords: Dielectrics; LTCC; Co-fireable; Low loss; High K

\section{INTRODUCTION}

Rapid growth in the application of LTCC technology for RF wireless is clearly driven by the trend of miniaturization and mobile communication systems. This technology provides the possibility for integration of passive components in a cost effective way. Increasing the density of integration by using materials for embedding components in a multilayer structure is strongly requested from circuit manufacturers. An increase in processor functionality is often linked with a numerical increase of passive components.

This paper discusses the ideas and some results of development work for a cofirable dielectric with a higher permitivity.

* An earlier version of this paper was published in the Proceedings of the 15th Annual European Passive Components Conference (CARTS-EUROPE 2001), 15-19 October 2001, pp. 213-218.

$\dagger$ Corresponding author. E-mail: Christina.Modes@heraeus.com 
The development was based on a project which was funded by the German government in a partnership of Heraeus, Siemens, BAM, IZM and TU Dresden. Each of these organisations was ideally placed to contribute to the outcome with either materials expertise or applications experience.

\section{DESCRIPTION OF THE DEVELOPMENT}

The goal was the development of an LTCC Tape with higher permitivity (further called "high-K tape") and combine it with a standard LTCC Tape (further called "base tape") for being able to produce LTCC circuits with embedded capacitors. Base tape and high-K tape were designed to sinter at different temperatures in order to get a two step sintering profile that would provide a self constraining behavior.

Before starting the development some restrictions were confirmed

1. Firing temperature $<900^{\circ} \mathrm{C}$ : Allows the usage of Ag- or alloyed Ag-pastes, which will fulfill the request for superior electrical conductivity.

2. Firing atmosphere: Air.

3. High K dielectric applied as a tape: Because of a tight thickness distribution requirement.

4. No lead in all dielectrics and conductors.

5. Recrystallizing base tape: Needs to be stable after additional refiring steps at $850^{\circ} \mathrm{C}$ to allow postfiring of conductor and resistor pastes.

Dielectric powders with a higher permitivity are available from the market but often need sintering temperatures typically $>1200^{\circ} \mathrm{C}$ for full densification.

In order to lower the sintering temperature of a high-K tape, additives like glasses or ceramic fluxes are needed. In general 2 different routes can be chosen:

Glass ceramic composite " $G C C$ "

Glass bonded ceramic " $G B C$ "

The main difference is the content and the function of the glass.

\begin{tabular}{lcc}
\hline & $G C C$ & $G B C$ \\
\hline Content of ceramic Vol\% & $35-40$ & $>90$ \\
Content of glass Vol\% & $60-65$ & $<10$ \\
Characteristic of the glass & $\begin{array}{c}\text { Tsoft }<800^{\circ} \mathrm{C} \text {, high } \mathrm{K} \\
\text { inert to the ceramic }\end{array}$ & $\begin{array}{c}\text { Very low working } \\
\text { point, reactive }\end{array}$ \\
\hline
\end{tabular}

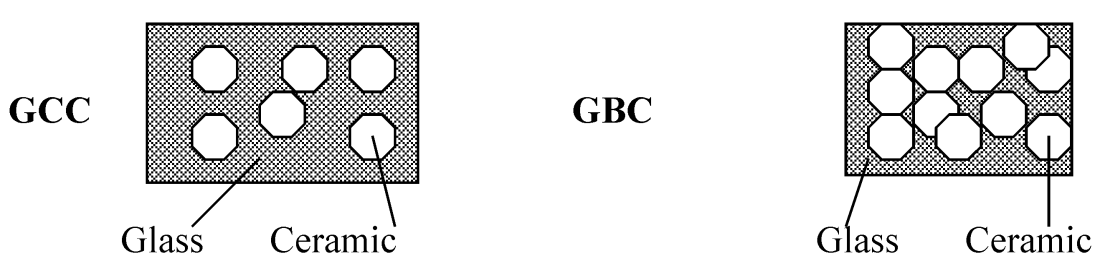

The material development initially followed both choices but latterly the GBC route has given the most promising materials.

The compatibility of cofired base tape with high-K tape is given by chemical compatibility and thermo-mechanical compatibility. 
During sintering the reactive components are the glasses. They are able to react with dielectric ceramic as well as with each other. Chemical compatibility is given if the reactions do not influence the electrical properties of either in a negative manner and the interface of the two dielectrics shows only a minor diffusion.

Thermo-mechanical compatibility requires the adjustment and matching of CTE (coeff. of thermal expansion) of both sintered high-K tape and base tape. The difference of the CTE's should below $1 \mathrm{ppm} / \mathrm{K}$. (A commonly accepted value from the glaze and ceramic industry).

Because of the high content of ceramic in the high-K tape coming from the GBC route, the CTE can not be easily adjusted. The CTE adjustment therefore was done in the base tape.

Besides the LTCC tape development, further investigation on cofiring Ag-pastes took place. Advanced inner layer Ag-pastes need excellent electrical conductivity together with a perfect adjustment in shrinkage and sintering behaviour. Any additive to promote or inhibit sintering will decrease the electrical conductivity and at a sintering temperature close or even at $900{ }^{\circ} \mathrm{C}, \mathrm{Ag}$-migration is also very critical. Very careful selection of additives in Ag-pastes has given good results with measured resistivity of $<2$ milliohm/sq at 10 microns fired thickness.

\section{Measured Data}

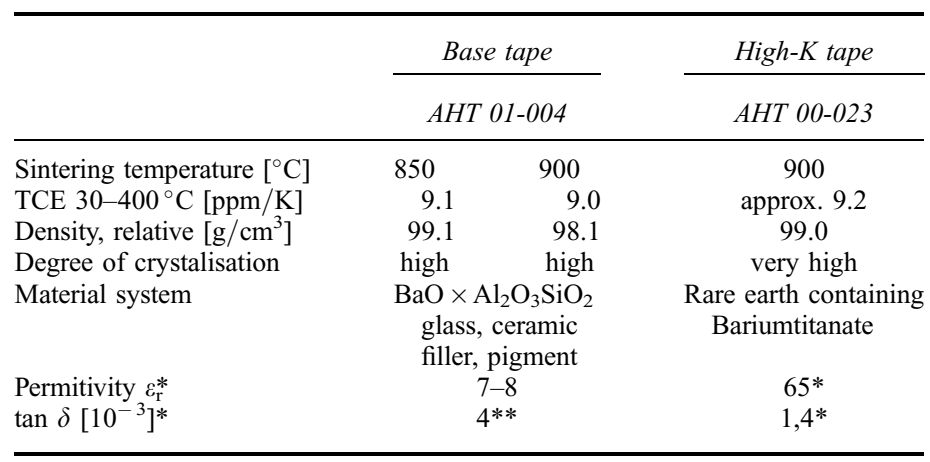

- Split post resonator at $3 \mathrm{GHz}, * * 6 \mathrm{GHz}$

Cross Section. A: high-K tape AHT00-023, B: cofiring Ag-conductor, C: base tape AHT01-004

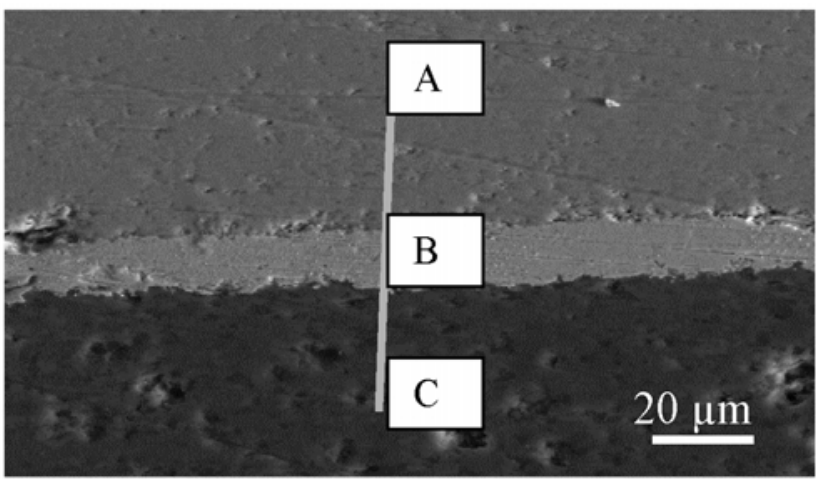




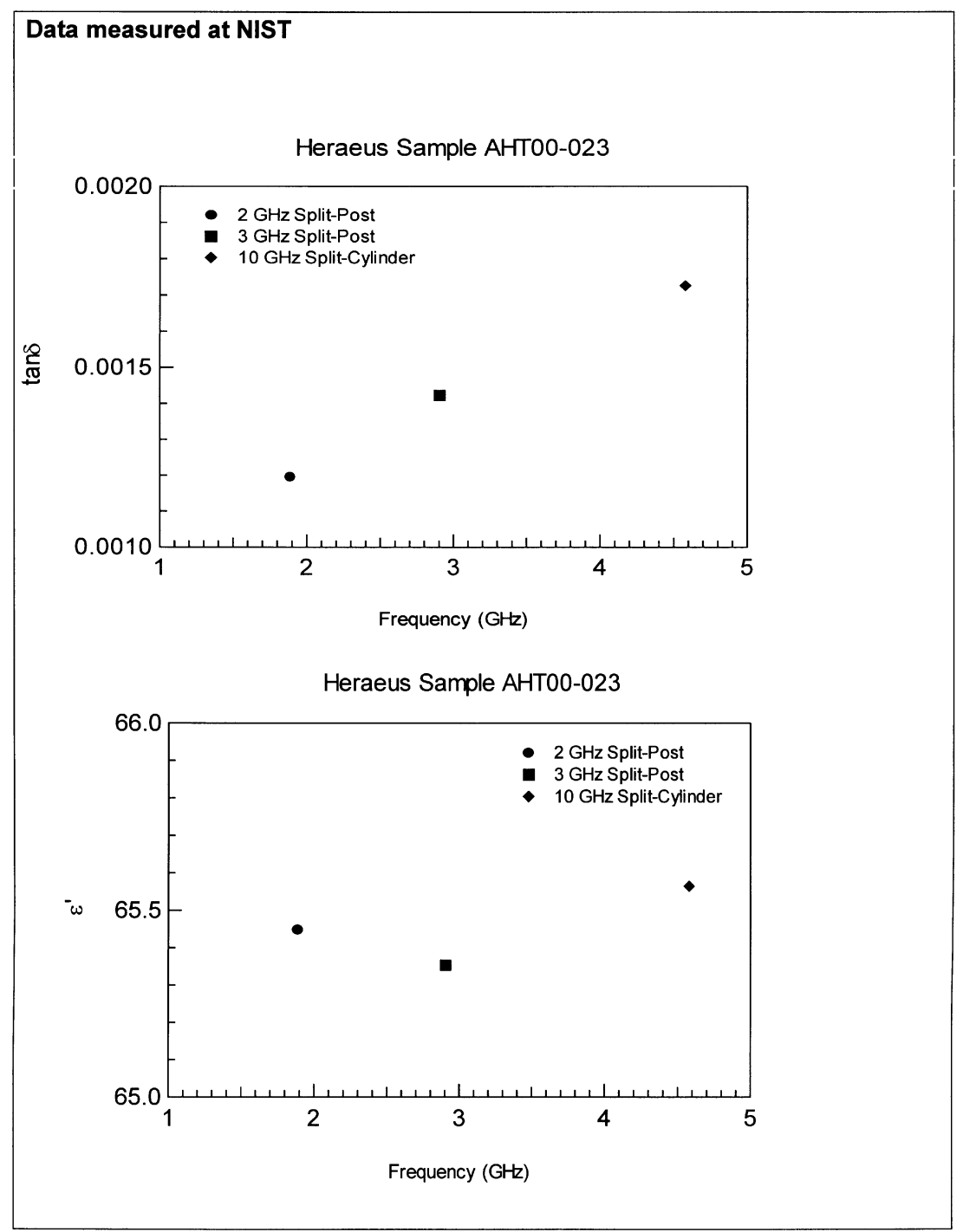

Materials System. The following material system called "Mixed K-System" was conceived for test circuits for testing under a range of differing conditions. This part of the program is still underway and will be reported in future communications.

"Mixed K-System" in development

Processing Conditions

\begin{tabular}{ll}
\hline Lamination & Burnout and sintering \\
\hline Isostatic Press & Box Furnace \\
Pressure: 210 bar $(3000 \mathrm{psi})$ & $25^{\circ} \mathrm{C}$ to $500^{\circ} \mathrm{C}$ at $2{ }^{\circ} \mathrm{C} / \mathrm{min}$. \\
Temperature: $70^{\circ} \mathrm{C}$ & Hold at $500^{\circ} \mathrm{C}$ for $30 \mathrm{~min}$. \\
Time: & $500^{\circ} \mathrm{C}$ to $900^{\circ} \mathrm{C}$ at $3{ }^{\circ} \mathrm{C} / \mathrm{min}$. \\
3 min. preheat & $\mathrm{Hold}$ at $900^{\circ} \mathrm{C}$ for $180 \mathrm{~min}$. \\
10 minutes at laminating pressure & $900^{\circ} \mathrm{C}$ to $25^{\circ} \mathrm{C}$ at $3{ }^{\circ} \mathrm{C} / \mathrm{min}$. \\
\hline
\end{tabular}




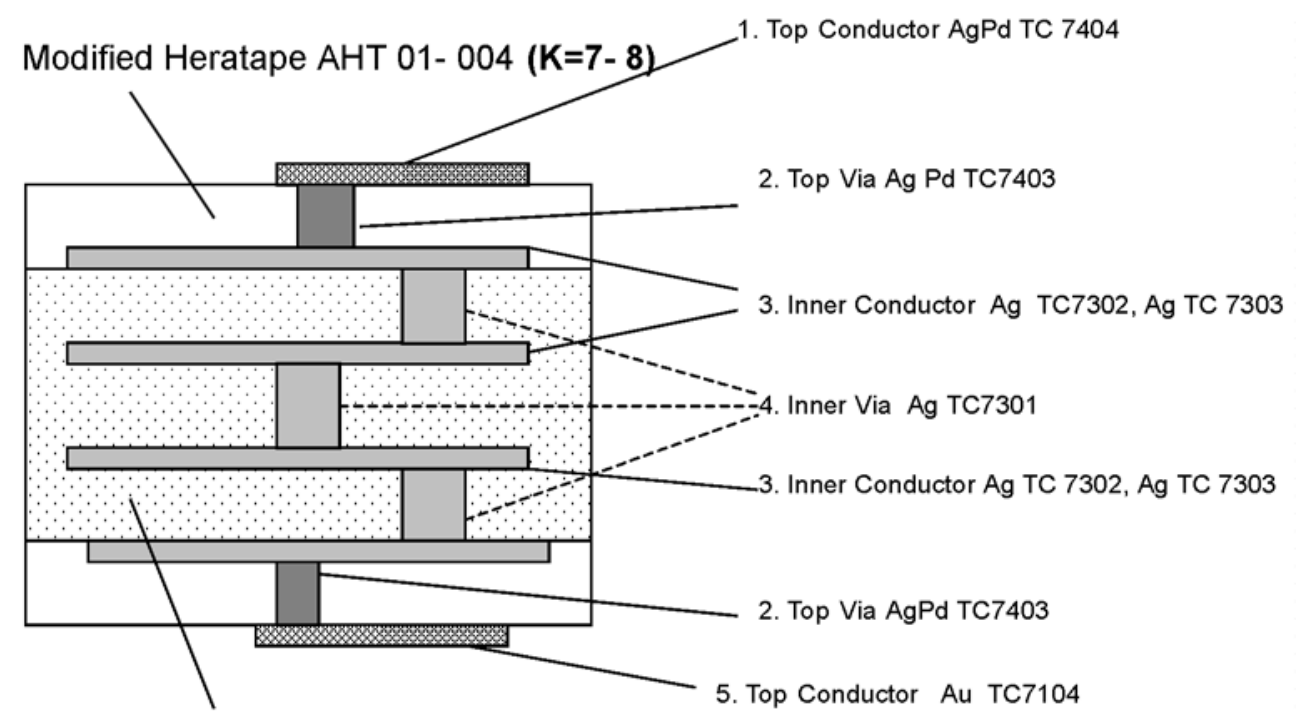

Heratape AHT 00-023 (K 65)

\section{RESULTS AND ADVANTAGES}

A complete material system with cofireable high $\mathrm{K}$ and low $\mathrm{K}$ dielectrics and conductors was successfully developed. Embedded capacitors in an LTCC circuit can therefore be more easily realised.

The maximum sintering temperature of $900^{\circ} \mathrm{C}$ allows the usage of $\mathrm{Ag}$ and $\mathrm{Ag}$-based pastes.

No Ag-migration was detected even after $180 \mathrm{~min}$ sintering time at $900{ }^{\circ} \mathrm{C}$.

The two dielectric material systems act to self constrain each other during the dual peak sintering process and this gives an $x, y$-shrinkage of $<5 \%$. This is highly advantageous in the manufacture of larger panel sizes where accurate prediction of feature location is required for subsequent processing of post fired materials and/or component placement.

The high- $k$ tape has a $\tan \delta$ of $1.4 \times 10^{-3}$. This makes this material system suitable for capacitors operating at RF.

\section{OUTLOOK}

This system will be capable of providing embedded capacitors that operate at RF. Circuits themselves will be manufactured in a process that gives low shrinkage for free sintered LTCC. This will facilitate assembly to post fired panels and provide a higher circuit density per area of green tape that has traditionally been possible with free sintered material. Future work will combine this materials system with the "KQ" range of photo-processed conductors to allow for fine line structures within and on top of "Mixed K-System". 

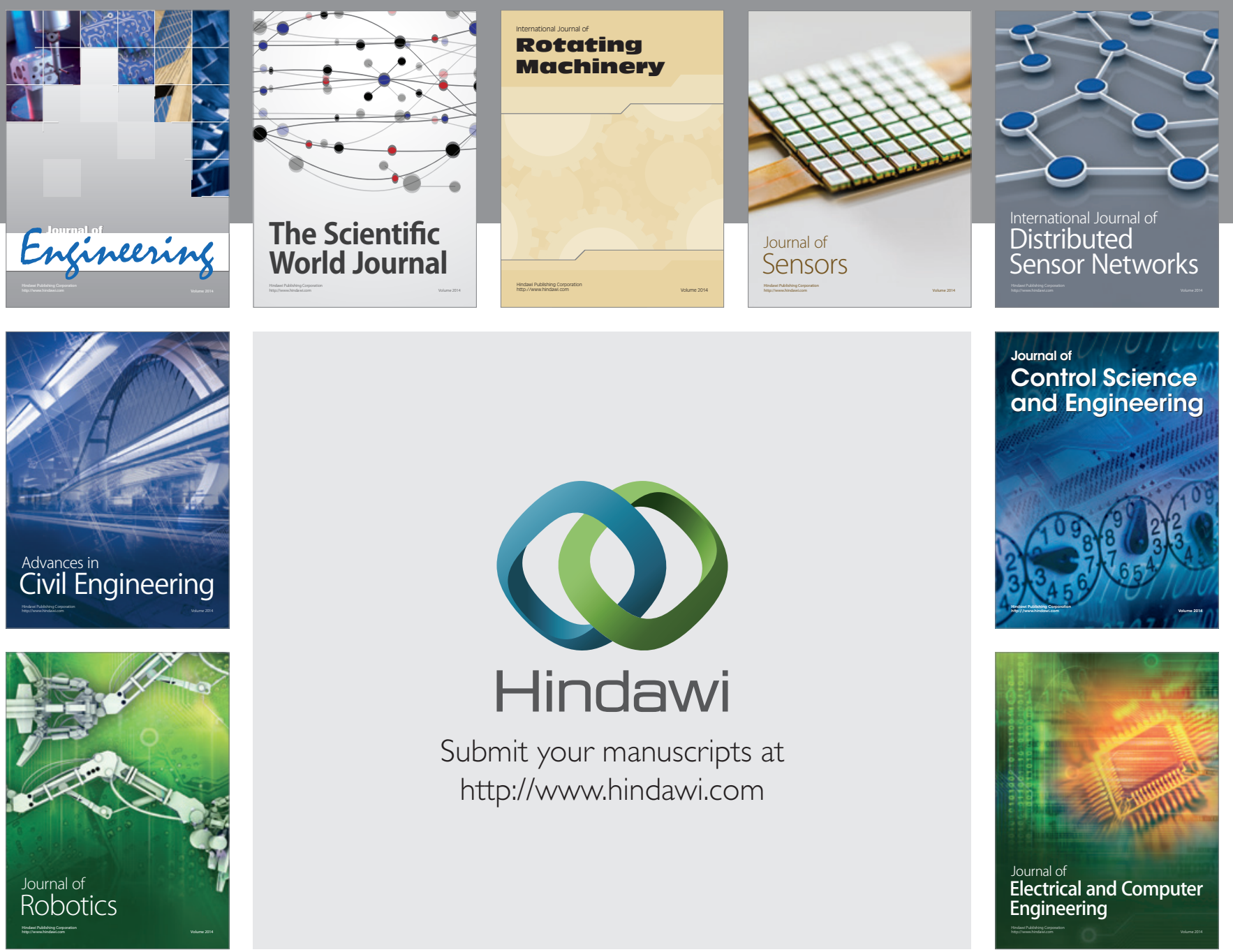

Submit your manuscripts at

http://www.hindawi.com
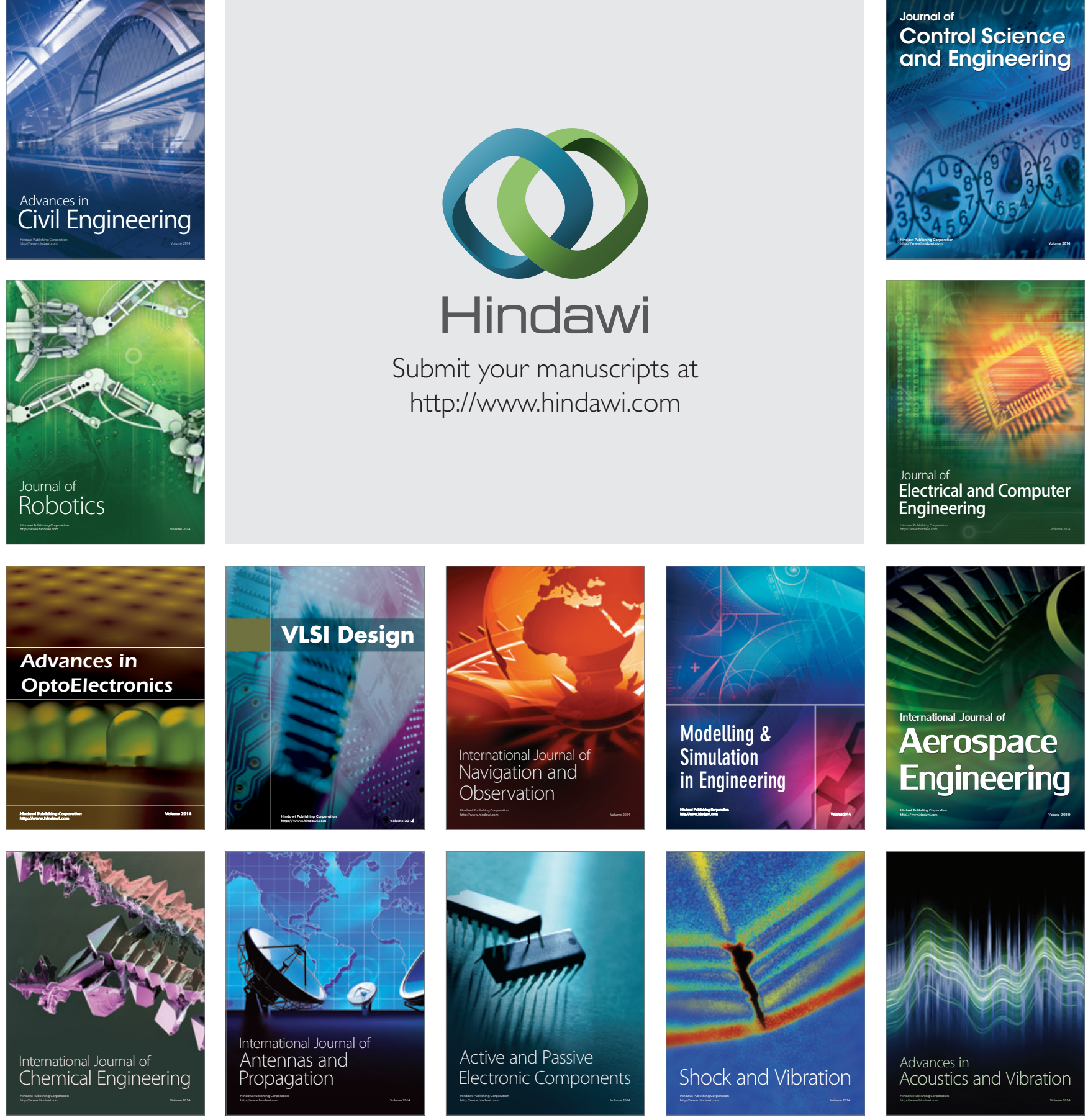